\title{
OSCILLATION OF UNFORCED IMPULSIVE NEUTRAL DELAY DIFFERENTIAL EQUATIONS OF FIRST ORDER
}

\author{
SHYAM S. SANTRA ${ }^{1}$ AND ARUN K. TRIPATHY ${ }^{2}$ \\ ${ }^{1}$ Centre for Systems, Dynamics and Control \\ College of Engineering, Mathematics and Physical Sciences \\ Harrison Building, University of Exeter \\ Exeter, EX4 4QF, UNITED KINGDOM \\ ${ }^{1,2}$ Department of Mathematics \\ Sambalpur University \\ Sambalpur, 768019, INDIA
}

ABSTRACT: In this work, we study the oscillatory behavior of solutions of a class of first order impulsive neutral delay differential equations of the form

$$
\begin{aligned}
& (y(t)-p(t) y(t-\tau))^{\prime}+q(t) G(y(t-\sigma))=0, \quad t \neq t_{k}, t \geq t_{0} \\
& \Delta y\left(t_{k}\right)=y\left(t_{k}^{+}\right)-y\left(t_{k}\right)=b_{k} y\left(t_{k}\right), \quad k=1,2,3, \cdots \\
& \Delta y\left(t_{k}-\tau\right)=y\left(t_{k}^{+}-\tau\right)-y\left(t_{k}-\tau\right)=b_{k} y\left(t_{k}-\tau\right), \quad k=1,2,3, \cdots
\end{aligned}
$$

for all $p(t)$ with $|p(t)|<\infty$.

\section{AMS Subject Classification: $34 \mathrm{~K}$}

Key Words: oscillation, nonoscillation, nonlinear, neutral, impulsive differential equation

Received: February 26, 2017; Accepted: September 4, 2018 ;

Published: September 11, 2018. doi: 10.12732/caa.v22i4.5

Dynamic Publishers, Inc., Acad. Publishers, Ltd. http://www.acadsol.eu/caa 


\section{INTRODUCTION}

Oscillation properties of linear impulsive differential equations with a single delay were first investigated by Gopalsamy and Zhang [6]. Later papers devoted to oscillatory behavior of linear impulsive differential equations with one or more delays came to exist in the literature (see for e.g [2]-[5], [13], [14] and [26]). But, we find very few papers on the oscillation of impulsive delay differential equations of neutral type. It is worth observation that the study of oscillation properties of neutral impulsive delay differential equations is more complicated than so called the oscillation properties of delay differential equations without impulses.

Tripathy, Santra and Pinelas [18, 20] have considered the first order impulsive differential system of the form

$$
(E)\left\{\begin{array}{l}
(y(t)+p(t) y(t-\tau))^{\prime}+q(t) G(y(t-\sigma))=0, t \neq \tau_{k}, k \in \mathbb{N} \\
\Delta\left(y\left(\tau_{k}\right)+p\left(\tau_{k}\right) y\left(\tau_{k}-\tau\right)\right)+r\left(\tau_{k}\right) G\left(y\left(\tau_{k}-\sigma\right)\right)=0, \quad k \in \mathbb{N},
\end{array}\right.
$$

where $\tau>0, \sigma \geq 0$ are real constants, $G \in C(\mathbb{R}, \mathbb{R})$ is nondecreasing such that $x G(x)>0$ for $x \neq 0, q, r \in C\left(\mathbb{R}_{+}, \mathbb{R}_{+}\right), \tau_{k}, k \in \mathbb{N}$ are the fixed moments of impulsive effect with the properties $0<\tau_{1}<\tau_{2}<\cdots, \lim _{k \rightarrow \infty} \tau_{k}=\infty$, $p \in P C\left(\mathbb{R}_{+}, \mathbb{R}\right), p\left(\tau_{k}\right), r\left(\tau_{k}\right)$ are constants for $k \in \mathbb{N}$, and $\Delta$ is the difference operator defined by

$$
\begin{aligned}
& \Delta\left(y\left(\tau_{k}\right)+p\left(\tau_{k}\right) y\left(\tau_{k}-\tau\right)\right) \\
& =y\left(\tau_{k}+0\right)+p\left(\tau_{k}\right) y\left(\tau_{k}-\tau+0\right)-y\left(\tau_{k}-0\right)-p\left(\tau_{k}\right) y\left(\tau_{k}-\tau-0\right), \\
& y\left(\tau_{k}-0\right)=y\left(\tau_{k}\right) \text { and } y\left(\tau_{k}-\tau-0\right)=y\left(\tau_{k}-\tau\right), \quad k \in \mathbb{N} .
\end{aligned}
$$

They have established the sufficient condition for oscillation and necessary and sufficient conditions for asymptotic behavior of solutions of $(E)$. It is interesting to note that the impulse $\tau_{k}, k \in \mathbb{N}$ for $y(t)$ satisfy another discrete neutral equation. Unlike the impulse for $(E)$, our objective in this work is to study the oscillatory behavior of a class of first order impulsive differential equations governing the impulse effect of the form

$$
\begin{aligned}
& (y(t)-p(t) y(t-\tau))^{\prime}+q(t) G(y(t-\sigma))=0, t \neq t_{i}, t \geq t_{0} \\
& \Delta y\left(t_{k}\right)=y\left(t_{k}^{+}\right)-y\left(t_{k}\right)=b_{k} y\left(t_{k}\right), k=1,2,3, \cdots
\end{aligned}
$$




$$
\Delta y\left(t_{k}-\tau\right)=y\left(t_{k}^{+}-\tau\right)-y\left(t_{k}-\tau\right)=b_{k} y\left(t_{k}-\tau\right), k=1,2,3, \cdots
$$

for various ranges of $p(t)$, where $b_{k} \neq 0$ for $k=1,2,3, \cdots$. With the system (1)-(3), we associate an initial condition of the form

$$
y_{t_{0}}=\phi(s), \quad s \in[-\rho, 0] ; \quad \rho=\max \{\tau, \sigma\}, t_{0}>\rho,
$$

where $y_{t_{0}}=y\left(t_{0}+s\right)$ for $-\rho \leq s \leq 0$ and $\phi \in P C([-\rho, 0], \mathbb{R})=\{\phi:[-\rho, 0] \rightarrow$ $\mathbb{R} \backslash \phi\}$ is continuous everywhere except at a finite number of points $\bar{s}$, where $\phi\left(\bar{s}^{+}\right)$and $\phi\left(\bar{s}^{-}\right)=\lim _{s \rightarrow \bar{s}^{-}} \phi(\bar{s})$ exist with $\phi\left(\bar{s}^{-}\right)=\phi(\bar{s})$.

Gopalsamy and Zhang [6] have studied the oscillatory behavior of solutions of

$$
\left\{\begin{array}{l}
y^{\prime}(t)+q(t) y(t-\sigma)=0, t \neq t_{i}, t \geq t_{0} \\
\Delta y\left(t_{k}\right)=y\left(t_{k}^{+}\right)-y\left(t_{k}\right)=b_{k} y\left(t_{k}\right), k=1,2,3, \cdots
\end{array}\right.
$$

Graef et al. [8] have considered

$$
\left\{\begin{array}{l}
(y(t)-p(t) y(t-\tau))^{\prime}+q(t)|y(t-\sigma)|^{\lambda} \operatorname{sgn} y(t-\sigma)=0, t \geq t_{0} \\
y\left(t_{k}^{+}\right)=b_{k} y\left(t_{k}\right), k=1,2,3, \cdots
\end{array}\right.
$$

and established sufficient conditions for oscillation of all solution of the systems (6) when $p(t) \in P C\left(\left[t_{0}, \infty\right), \mathbb{R}^{+}\right)$only. In an another work [15], Shen and Zou have studied oscillation properties of first order impulsive neutral delay differential equations with positive and negative coefficients of the form

$$
\left\{\begin{array}{l}
(y(t)-p(t) y(t-\tau))^{\prime}+q(t) y\left(t-\sigma_{1}\right)-v(t) y\left(t-\sigma_{2}\right)=0, \sigma_{1} \geq \sigma_{2}>0, t \geq t_{0} \\
y\left(t_{k}^{+}\right)=I_{k}\left(y\left(t_{k}\right)\right), k=1,2,3, \cdots
\end{array}\right.
$$

and obtained sufficient conditions for oscillation of $(7)$ when $p(t) \in P C\left(\left[t_{0}, \infty\right)\right.$, $\mathbb{R}^{+}$).

For the above works [8] and [15] we have a common question:

$(Q)$ Can we find some oscillation criteria for (6) and (7) when $p(t) \in P C\left(\left[t_{0}\right.\right.$, $\left.\infty), \mathbb{R}^{-}\right) ?$

Motivated by the above works, we have made an attempt here to study the oscillatory behavior of all solution of (1)-(3) for all ranges of $p(t)$ with $|p(t)|<\infty$ and throughout the work we use the following hypothesis: 
$\left(A_{0}\right)$ there exists a constant $L>0$ such that $|G(x)| \geq L|x|, x \in \mathbb{R}$,

that is, in particular

$$
G(x)=x\left(L+|x|^{\mu}\right), x \in \mathbb{R}, \mu>0 .
$$

Not only our work gives an answer to the question $(Q)$, but also deserve a more general work than that of [6], [8] and [15]. We note that (5), (6) and (7) are the special cases of (1). In this direction we refer some of the works (see for e.g. [1], [7], [9]-[12], [16], [17], [22]-[25], [27]) to the reader and references cited therein.

Definition 1.1. A real-valued function $y(t)$ is called a solution corresponding to $t_{0}$ of the value problem (1)-(3) if:

(i) $y(t)=\phi\left(t-t_{0}\right)$ for $t_{0}-\rho \leq t \leq t_{0}, y(t)$ is continuous for $t \geq t_{0}$ and $t \neq t_{k}, k=1,2, \cdots$

(ii) $(y(t)-p(t) y(t-\tau))$ is continuously differentiable for $t>t_{0}, t \neq t_{k}$, $t \neq t_{k}+\tau, t \neq t_{k}+\sigma, k=1,2, \cdots$, and satisfies (1);

(iii) $y\left(t_{k}^{+}\right), y\left(t_{k}^{-}\right), y\left(t_{k}^{+}-\tau\right)$ and $y\left(t_{k}^{-}-\tau\right)$ exist, $y\left(t_{k}^{-}\right)=y\left(t_{k}\right), y\left(t_{k}^{-}-\tau\right)=$ $y\left(t_{k}-\tau\right)$, and (2)-(3) are satisfied.

Definition 1.2. A solution $y(t)$ of (1)-(3) is said to be nonoscillatory if it is eventually positive or eventually negative, and it is said to be oscillatory otherwise.

\section{MAIN RESULTS}

In this section, we establish sufficient condition for oscillation of all solutions of (1)-(3). We need the following two lemmas for our use in the sequel. Although the proofs are similar to [8], still we have given here for our completeness.

Lemma 2.1. Let $p(t) \geq 0, t \in \mathbb{R}^{+}$and $b_{k}>0$. Assume that there exists a sequence $\left\{s_{n}\right\}$ such that $s_{n} \in\left(t_{n}, t_{n+1}\right], s_{n+1}-s_{n}=\tau, p\left(s_{n}\right)>0$ for 
$n=1,2,3, \cdots$ and

$$
\sum_{i=1}^{\infty} \prod_{j=1}^{i} \frac{\left(1+b_{j}\right)}{p\left(s_{j}\right)}=\infty
$$

Furthermore, assume that

$$
\left\{\begin{array}{l}
p\left(t_{k}^{+}\right) \geq\left(1+b_{k}\right) p\left(t_{k}\right), t_{k}-\tau \neq t_{i}, i<k \\
\left(1+b_{k}^{*}\right) p\left(t_{k}^{+}\right) \geq\left(1+b_{k}\right) p\left(t_{k}\right), t_{k}-\tau=t_{i}, i<k
\end{array}\right.
$$

where $1+b_{k}^{*}=\left\{1+b_{i}: t_{k}-\tau=t_{i}, i<k\right\}$. Let $y(t)$ be a solution of $(1)-(2)$ such that $y(t)>0, y(t-\rho)>0$ for $t \geq t_{0}>\rho$. Then $z\left(t_{k}^{+}\right) \geq 0$ for $t \in\left(t_{k}, t_{k+1}\right]$, $k \geq 0$. In addition, $z(t)>0$ for $t \geq t_{0}$, where

$$
z(t)=y(t)-p(t) y(t-\tau)
$$

Proof. From (1), it follows that

$$
z^{\prime}(t)=-q(t) G(y(t-\sigma)) \leq 0, t \geq t_{0}
$$

that is, $z(t)$ is nonincreasing on $\left[t_{0}, \infty\right)$. Because of $(1)$ and using the fact that $y\left(t_{i}^{+}\right)=\left(1+b_{k}^{*}\right) y\left(t_{i}\right)$ for $i<k$ and $t_{k}-\tau=t_{i}$, we get

$$
\begin{aligned}
z\left(t_{k}^{+}\right) & =y\left(t_{k}^{+}\right)-p\left(t_{k}^{+}\right) y\left(t_{k}^{+}-\tau\right) \\
& =\left(1+b_{k}\right) y\left(t_{k}\right)-p\left(t_{k}^{+}\right)\left(1+b_{k}^{*}\right) y\left(t_{k}-\tau\right) \\
& \leq\left(1+b_{k}\right) y\left(t_{k}\right)-p\left(t_{k}\right)\left(1+b_{k}\right) y\left(t_{k}-\tau\right) \\
& =\left(1+b_{k}\right) z\left(t_{k}\right)
\end{aligned}
$$

and when $t_{k}-\tau \neq t_{i}, i<k$

$$
\begin{aligned}
z\left(t_{k}^{+}\right) & =y\left(t_{k}^{+}\right)-p\left(t_{k}^{+}\right) y\left(t_{k}^{+}-\tau\right) \\
& =\left(1+b_{k}\right) y\left(t_{k}\right)-p\left(t_{k}^{+}\right) y\left(t_{k}-\tau\right) \\
& \leq\left(1+b_{k}\right) y\left(t_{k}\right)-p\left(t_{k}\right)\left(1+b_{k}\right) y\left(t_{k}-\tau\right) \\
& =\left(1+b_{k}\right) z\left(t_{k}\right)
\end{aligned}
$$

Therefore,

$$
z\left(t_{k}^{+}\right) \leq\left(1+b_{k}\right) z\left(t_{k}\right), k=1,2,3, \cdots
$$


First we claim that $z\left(t_{k}\right) \geq 0$ for $k \geq 1$. If not, there exists $m \geq 1$ such that $z\left(t_{m}\right)<0$. Since $z(t)$ is nonincreasing on $\left[t_{0}, \infty\right)$, then there exists $\mu>0$ such that $z\left(t_{m}\right)=-\mu$. Consequently, $z\left(t_{m}^{+}\right) \leq-\mu\left(1+b_{m}\right)$. Indeed, $z(t)<z\left(t_{m}^{+}\right) \leq-\mu\left(1+b_{m}\right)$ for $t_{m}<t \leq t_{m+1}$. Further,

$$
\begin{aligned}
z\left(t_{m+1}^{+}\right) & \leq\left(1+b_{m+1}\right) z\left(t_{m+1}\right) \\
& \leq\left(1+b_{m+1}\right) z\left(t_{m}^{+}\right) \\
& \leq-\mu\left(1+b_{m}\right)\left(1+b_{m+1}\right)
\end{aligned}
$$

implies that

$$
z(t)<z\left(t_{m+1}^{+}\right) \leq-\mu\left(1+b_{m}\right)\left(1+b_{m+1}\right)
$$

for $t_{m+1}<t \leq t_{m+2}$. Proceeding inductively, it is easy to see that

$$
z(t)<z\left(t_{m+n+1}^{+}\right) \leq-\mu\left(1+b_{m}\right)\left(1+b_{m+1}\right) \cdots\left(1+b_{m+n+1}\right)
$$

for $t_{m+n}<t \leq t_{m+n+1}, n=0,1,2, \cdots$. Now,

$$
\begin{aligned}
y\left(s_{m+n}\right) & =z\left(s_{m+n}\right)+p\left(s_{m+n}\right) y\left(s_{m+n-1}\right) \\
& \leq z\left(t_{m+n}^{+}\right)+p\left(s_{m+n}\right) y\left(s_{m+n-1}\right) \\
& \leq-\mu\left(1+b_{m}\right)\left(1+b_{m+1}\right) \cdots\left(1+b_{m+n}\right)+p\left(s_{m+n}\right) y\left(s_{m+n-1}\right)
\end{aligned}
$$

Applying the above relation recursively, we get

$$
\begin{aligned}
y\left(s_{m+n}\right) \leq-\mu & {\left[\left(1+b_{m}\right)\left(1+b_{m+1}\right) \cdots\left(1+b_{m+n}\right)\right.} \\
& +p\left(s_{m+n}\right)\left(1+b_{m}\right)\left(1+b_{m+1}\right) \cdots\left(1+b_{m+n-1}\right) \\
& +p\left(s_{m+n}\right) p\left(s_{m+n-1}\right)\left(1+b_{m}\right)\left(1+b_{m+1}\right) \cdots\left(1+b_{m+n-2}\right) \\
& +\cdots \\
& \left.+p\left(s_{m+n}\right) p\left(s_{m+n-1}\right) \cdots p\left(s_{m+2}\right)\left(1+b_{m}\right)\left(1+b_{m+1}\right)\right] \\
& +p\left(s_{m+n}\right) p\left(s_{m+n-1}\right) \cdots p\left(s_{m+1}\right) y\left(s_{m}\right) \\
& =\prod_{j=1}^{m} p\left(s_{m+j}\right)\left[y\left(s_{m}\right)-\left(1+b_{m}\right) \mu \sum_{i=1}^{n} \prod_{j=1}^{i} \frac{\left(1+b_{m+j}\right)}{p\left(S_{m+j}\right)}\right] .
\end{aligned}
$$

Consequently, $y\left(s_{m+n}\right)<0$ for sufficiently large $n$, a contradiction. Hence $z\left(t_{k}\right) \geq 0$ for $k \geq 1$. Since $z(t) \geq z\left(t_{1}\right)$ for $t_{0} \leq t \leq t_{1}$, then it follows that 
$z\left(t_{0}\right) \geq 0$. On the otherhand, $z(t) \geq z\left(t_{k+1}\right) \geq 0$ for $t_{k}<t \leq t_{k+1}$ implies that $z\left(t_{k}^{+}\right) \geq 0$ and hence $z(t) \geq 0$ for $t \in\left(t_{k}, t_{k+1}\right], k \geq 0$.

Finally, we prove that $z(t)>0$ for $t \geq t_{0}$. For this we need to claim that $z\left(t_{k}\right)>0, k \geq 0$. If this is not true, let there exists $m \geq 0$ such that $z\left(t_{m}\right)=0$. Integrating (3) from $t_{m}$ to $t_{m+1}$, we obtain

$$
\begin{aligned}
z\left(t_{m+1}\right) & =z\left(t_{m}^{+}\right)-\int_{t_{m}}^{t_{m+1}} q(s) G(y(s-\sigma)) d s \\
& \leq\left(1+b_{m}\right) z\left(t_{m}\right)-\int_{t_{m}}^{t_{m+1}} q(s) G(y(s-\sigma)) d s \\
& =-\int_{t_{m}}^{t_{m+1}} q(s) G(y(s-\sigma)) d s
\end{aligned}
$$

a contradiction. Ultimately, $z\left(t_{k}\right)>0$ for $k \geq 0$. Hence $z(t)>0$ for $t \geq t_{0}$ due to the fact that $z(t) \geq z\left(t_{k+1}\right)>0$ for $t \in\left(t_{k}, t_{k+1}\right]$. This completes the proof of the lemma.

Lemma 2.2. Let $-1<b_{k} \leq 0, k=1,2,3, \cdots$. Assume that there exists a sequence $\left\{s_{n}\right\}$ such that $s_{n} \in\left(t_{n}, t_{n+1}\right], s_{n+1}-s_{n}=\tau, p\left(s_{n}\right)>0$ for $n=1,2,3, \cdots$ and

$$
\sum_{i=1}^{\infty} \prod_{j=1}^{i} \frac{1}{p\left(s_{j}\right)}=\infty
$$

Furthermore, suppose that

$$
\left\{\begin{array}{l}
p\left(t_{k}^{+}\right) \geq p\left(t_{k}\right), t_{k}-\tau \neq t_{i}, i<k \\
\left(1+b_{k}^{*}\right) p\left(t_{k}^{+}\right) \geq p\left(t_{k}\right), t_{k}-\tau=t_{i}, i<k
\end{array}\right.
$$

where $\left(1+b_{k}^{*}\right)$ is defined in Lemma 2.1. Let $y(t)$ be a solution of $(1)-(2)$ such that $y(t)>0, y(t-\rho)>0$ for $t \geq t_{0}>\rho$ and let $z(t)$ be defined by (2). Then $z(t)>0$ for all $t \geq t_{0}$.

Proof. Since $1+b_{k}>0$, then the proof of the lemma follows from the proof of Lemma 2.1 and hence the details are omitted.

Theorem 2.3. Let $p(t) \geq 0, t \in \mathbb{R}_{+}$and $\left(A_{0}\right)$ hold. Assume the conditions of Lemma 2.1. Furthermore, assume that $\left(A_{1}\right) t_{k+1}-t_{k} \geq T, \quad k=1,2, \cdots$. 
If either

$\left(A_{2}\right) \lim \sup _{k \rightarrow \infty}\left(\frac{1}{1+b_{k}} \int_{t_{k}}^{t_{k}+T} q(s) d s\right)>\frac{1}{L}, \sigma \geq T>0$

or

$\left(A_{3}\right) \lim \sup _{k \rightarrow \infty}\left(\frac{1}{1+b_{k}} \int_{t_{k}}^{t_{k}+\sigma} q(s) d s\right)>\frac{1}{L}, 0<\sigma<T$

holds, then every solution of (1)-(2) is oscillatory.

Proof. On the contrary, let's assume that $y(t)$ is a nonoscillatory solution of (1)-(2). Without loss of generality, we assume that $y(t)>0, y(t-\rho)>0$ for $t \geq t_{0}$. By Lemma 2.1, $z(t) \geq 0$ for $t \in\left(t_{k}, t_{k+1}\right], k=0,1,2, \ldots$. We have the following two possible cases.

Case 1. $(\sigma \geq T>0)$ Integrating (3) from $t_{k}$ to $t_{k}+T$ and then using the fact that $z(t) \leq y(t)$, we obtain

$$
z\left(t_{k}+T\right)-z\left(t_{k}^{+}\right)+\int_{t_{k}^{+}}^{t_{k}+T} q(s) G(z(s-\sigma)) d s \leq 0 .
$$

Indeed, $s-\sigma \leq t_{k}+T-\sigma$ and $\sigma \geq T$ implies that $t_{k}+T-\sigma \leq t_{k}$ and hence due to $\left(A_{0}\right)$ the preceding inequality becomes

$$
z\left(t_{k}+T\right)-z\left(t_{k}^{+}\right)+L z\left(t_{k}\right) \int_{t_{k}^{+}}^{t_{k}+T} q(s) d s \leq 0,
$$

that is,

$$
z\left(t_{k}+T\right)-z\left(t_{k}^{+}\right)+L \frac{z\left(t_{k}^{+}\right)}{1+b_{k}} \int_{t_{k}^{+}}^{t_{k}+T} q(s) d s \leq 0
$$

due to (4). Therefore,

$$
z\left(t_{k}+T\right)+z\left(t_{k}^{+}\right)\left[\frac{L}{1+b_{k}} \int_{t_{k}^{+}}^{t_{k}+T} q(s) d s-1\right] \leq 0
$$

is not possible due to $\left(A_{2}\right)$.

Case 2. $(0<\sigma<T)$ Integrating (3) from $t_{k}$ to $t_{k}+\sigma$, we obtain

$$
z\left(t_{k}+\sigma\right)-z\left(t_{k}^{+}\right)+\int_{t_{k}^{+}}^{t_{k}+\sigma} q(s) G(z(s-\sigma)) d s \leq 0 .
$$

Using the fact that $t_{k}+\sigma \geq s$, that is, $s-\sigma \leq t_{k}$, it follows from (5) that

$$
z\left(t_{k}+\sigma\right)-z\left(t_{k}^{+}\right)+L z\left(t_{k}\right) \int_{t_{k}^{+}}^{t_{k}+\sigma} q(s) d s \leq 0,
$$


that is,

$$
z\left(t_{k}+\sigma\right)+z\left(t_{k}^{+}\right)\left[\frac{L}{1+b_{k}} \int_{t_{k}^{+}}^{t_{k}+\sigma} q(s) d s-1\right] \leq 0
$$

which is not possible due to $\left(A_{3}\right)$. Hence the proof of the theorem is complete.

Theorem 2.4. Let $-\infty<-a \leq p(t) \leq 0$ for $t \in \mathbb{R}_{+}$and $b_{k}>0$. Assume that $\left(A_{0}\right),\left(A_{1}\right)$ and $\left(A_{4}\right) Q(t)=\min \{q(t), q(t-\tau)\}, t \geq \tau$, $\left(A_{5}\right)\left\{\begin{array}{l}p\left(t_{k}^{+}-\tau\right) \geq\left(1+b_{k}\right) p\left(t_{k}-\tau\right), t_{k}-2 \tau \neq t_{i}, i<k \\ \left(1+b_{k}^{*}\right) p\left(t_{k}^{+}-\tau\right) \geq\left(1+b_{k}\right) p\left(t_{k}-\tau\right), t_{k}-2 \tau=t_{i}, i<k,\end{array}\right.$ where $1+b_{k}^{*}=\left\{1+b_{i}: t_{k}-2 \tau=t_{i}, i<k\right\}$ hold. If either $\left(A_{6}\right) \lim \sup _{k \rightarrow \infty}\left(\frac{1}{1+b_{k}} \int_{t_{k}}^{t_{k}+T} Q(s) d s\right)>\frac{1+a}{L}, \sigma \geq T>0, \sigma-\tau \geq T$ or $\left(A_{7}\right) \lim \sup _{k \rightarrow \infty}\left(\frac{1}{1+b_{k}} \int_{t_{k}}^{t_{k}+\tau} Q(s) d s\right)>\frac{1+a}{L}, 2 \tau<\sigma<T$ holds, then every solution of (1)-(3) oscillates.

Proof. Proceeding as in the proof of Theorem 2.3, we get (3). Hence $z(t)$ is nonincreasing on $\left[t_{0}, \infty\right)$. It is easy to see that

$$
\begin{aligned}
0 & =z^{\prime}(t)+q(t) G(y(t-\sigma))+a z^{\prime}(t-\tau)+a q(t-\tau) G(y(t-\tau-\sigma)) \\
& \geq z^{\prime}(t)+a z^{\prime}(t-\tau)+L Q(t)[y(t-\sigma)+a y(t-\tau-\sigma)] \\
& \geq z^{\prime}(t)+a z^{\prime}(t-\tau)+L Q(t) z(t-\sigma) .
\end{aligned}
$$

Case 1. $(\sigma \geq T>0, \quad \sigma-\tau \geq T>0)$ Integrating (6) on $\left(t_{k}, t_{k}+T\right)$, we obtain

$$
\begin{aligned}
z\left(t_{k}+T\right)-z\left(t_{k}^{+}\right)+a z\left(t_{k}+T-\tau\right)-a z\left(t_{k}^{+}-\tau\right) & \\
& +L \int_{t_{k}^{+}}^{t_{k}+T} Q(s) z(s-\sigma) d s \leq 0 .
\end{aligned}
$$

Using the arguments as in the proof of Lemma 2.1, it follows that $z(t)>0$, $t \in\left(t_{k}, t_{k+1}\right]$. Indeed, $z\left(t_{k}+T\right) \leq z\left(t_{k}+T-\tau\right), z\left(t_{k}^{+}\right) \leq z\left(t_{k}^{+}-\tau\right)$ and $s \leq t_{k}+T$ implies that $s-\sigma \leq t_{k}+T-\sigma \leq t_{k}-\tau$ for which $z(s-\sigma) \geq z\left(t_{k}-\tau\right)$. Therefore,(7) becomes

$$
(1+a) z\left(t_{k}+T\right)-(1+a) z\left(t_{k}^{+}-\tau\right)+L z\left(t_{k}-\tau\right) \int_{t_{k}^{+}}^{t_{k}+T} Q(s) d s \leq 0 .
$$


Furthermore, $t_{k}-2 \tau \neq t_{i}$ for $i<k$ implies that

$$
\begin{aligned}
z\left(t_{k}^{+}-\tau\right) & =y\left(t_{k}^{+}-\tau\right)-p\left(t_{k}^{+}-\tau\right) y\left(t_{k}^{+}-2 \tau\right) \\
& =\left(1+b_{k}\right) y\left(t_{k}-\tau\right)-p\left(t_{k}^{+}-\tau\right) y\left(t_{k}-2 \tau\right) \\
& \leq\left(1+b_{k}\right) y\left(t_{k}-\tau\right)-\left(1+b_{k}\right) p\left(t_{k}-\tau\right) y\left(t_{k}-2 \tau\right) \\
& =\left(1+b_{k}\right) z\left(t_{k}-\tau\right)
\end{aligned}
$$

due to $\left(A_{5}\right)$ and $t_{k}-2 \tau=t_{i}$ for $i<k$ implies that

$$
\begin{aligned}
z\left(t_{k}^{+}-\tau\right) & =y\left(t_{k}^{+}-\tau\right)-p\left(t_{k}^{+}-\tau\right) y\left(t_{k}^{+}-2 \tau\right) \\
& =\left(1+b_{k}\right) y\left(t_{k}-\tau\right)-p\left(t_{k}^{+}-\tau\right)\left(1+b_{k}^{*}\right) y\left(t_{k}-2 \tau\right) \\
& \leq\left(1+b_{k}\right) y\left(t_{k}-\tau\right)-p\left(t_{k}-\tau\right)\left(1+b_{k}\right) y\left(t_{k}-2 \tau\right) \\
& =\left(1+b_{k}\right) z\left(t_{k}-\tau\right)
\end{aligned}
$$

due to $\left(A_{5}\right)$. Hence for all $\mathrm{k}$,

$$
z\left(t_{k}^{+}-\tau\right) \leq\left(1+b_{k}\right) z\left(t_{k}-\tau\right)
$$

Using (9) in (8), we get

$$
(1+a) z\left(t_{k}+T\right)+z\left(t_{k}^{+}-\tau\right)\left[\frac{L}{1+b_{k}} \int_{t_{k}^{+}}^{t_{k}+T} Q(s) d s-(1+a)\right] \leq 0
$$

which is not possible due to $\left(A_{6}\right)$.

Case 2. $(2 \tau<\sigma<T)$ Integrating (6) on $\left(t_{k}, t_{k}+\tau\right)$, we obtain

$$
z\left(t_{k}+\tau\right)-z\left(t_{k}^{+}\right)+a z\left(t_{k}\right)-a z\left(t_{k}^{+}-\tau\right)+L \int_{t_{k}^{+}}^{t_{k}+\tau} Q(s) z(s-\sigma) d s \leq 0,
$$

that is

$$
\begin{aligned}
z\left(t_{k}+\tau\right)-z\left(t_{k}^{+}-\tau\right)+a z\left(t_{k}+\tau\right)-a z\left(t_{k}^{+}-\tau\right) & \\
& +L \int_{t_{k}^{+}}^{t_{k}+\tau} Q(s) z(s-\sigma) d s \leq 0 .
\end{aligned}
$$

Consequently,

$$
(1+a) z\left(t_{k}+\tau\right)-(1+a) z\left(t_{k}^{+}-\tau\right)+L \int_{t_{k}^{+}}^{t_{k}+\tau} Q(s) z(s-\sigma) d s \leq 0 .
$$


Indeed, $s \leq t_{k}+\tau$ implies that $s-\sigma \leq t_{k}+\tau-\sigma \leq t_{k}-\tau$ and hence $z(s-\sigma) \geq z\left(t_{k}-\tau\right)$. Hence, (10) reduces to

$$
(1+a) z\left(t_{k}+\tau\right)+z\left(t_{k}^{+}-\tau\right)\left[\frac{L}{1+b_{k}} \int_{t_{k}^{+}}^{t_{k}+\tau} Q(s) d s-(1+a)\right] \leq 0
$$

which is not possible due to $\left(A_{7}\right)$ and $(9)$. Hence the proof of the theorem is complete.

Remark 2.5. In the above results, $1+b_{k}>0$ for $b_{k}>0$ and $k=1,2,3, \cdots$. If $-1<b_{k} \leq 0$, then also $1+b_{k}>0$. However, $1+b_{k} \leq 0$ when $-\infty<b_{k} \leq-1$ for $k=1,2,3, \cdots$. Indeed, $y\left(t_{k}^{+}\right)=\left(1+b_{k}\right) y\left(t_{k}\right)$ implies that $y\left(t_{k}^{+}\right) y\left(t_{k}\right)=$ $\left(1+b_{k}\right)\left(y\left(t_{k}\right)\right)^{2} \leq 0$ for $1+b_{k} \leq 0$ and $k=1,2,3, \cdots$. If the impulse $t_{k}$, $k=1,2,3, \cdots$ covers the intervals of the form $\left[t_{0}, \infty\right), t_{0}>\rho$, then $y(t)$ is oscillatory. Hence it is worth observation that $-1<b_{k}<\infty$. As $1+b_{k}>0$ for $-1<b_{k} \leq 0, k=1,2,3, \cdots$, in the following we state the results without proof.

Theorem 2.6. Let $p(t) \geq 0, t \in \mathbb{R}_{+}$. Assume that $\left(A_{0}\right),\left(A_{1}\right)$ and conditions of Lemma 2.2 hold. If either

$\left(A_{8}\right) \lim \sup _{k \rightarrow \infty}\left(\int_{t_{k}}^{t_{k}+T} q(s) d s\right)>\frac{1}{L}, \sigma \geq T>0$

or

$\left(A_{9}\right) \lim \sup _{k \rightarrow \infty}\left(\int_{t_{k}}^{t_{k}+\sigma} q(s) d s\right)>\frac{1}{L}, 0<\sigma<T$

holds, then every solution of (1)-(2) oscillates.

Theorem 2.7. Let $-\infty<-a \leq p(t) \leq 0$ for $t \in \mathbb{R}_{+}$. Assume that $\left(A_{0}\right),\left(A_{1}\right)$ and $\left(A_{4}\right)$ hold. Furthermore, assume the following:

$$
\left\{\begin{array}{l}
p\left(t_{k}^{+}-\tau\right) \geq\left(1+b_{k}\right) p\left(t_{k}-\tau\right), t_{k}-2 \tau \neq t_{i}, i<k \\
\left(1+b_{k}^{*}\right) p\left(t_{k}^{+}-\tau\right) \geq\left(1+b_{k}\right) p\left(t_{k}-\tau\right), t_{k}-2 \tau=t_{i}, i<k
\end{array}\right.
$$

where $1+b_{k}^{*}$ is defined in Theorem 2.4. If either $\left(A_{10}\right) \lim \sup _{k \rightarrow \infty}\left(\int_{t_{k}}^{t_{k}+T} Q(s) d s\right)>\frac{1+a}{L}, \sigma \geq T>0, \sigma-\tau \geq T$ or $\left(A_{11}\right) \lim \sup _{k \rightarrow \infty}\left(\int_{t_{k}}^{t_{k}+\tau} Q(s) d s\right)>\frac{1+a}{L}, 2 \tau<\sigma<T$ holds, then every solution of (1)-(3) oscillates.

We conclude this section with the following examples to show the feasibility and effectiveness of our main results. 
Example 2.8. Consider the system

$$
\left\{\begin{array}{l}
\left(y(t)-\frac{\ln (t+2)}{\ln (t+1)} y(t-3)\right)^{\prime}+(2+t) y(t-2)\left(1+|y(t-2)|^{\mu}\right)=0, t \geq 2 \\
y\left(t_{k}^{+}\right)=\frac{k+2}{k+1} y\left(t_{k}\right), k=1,2,3, \cdots
\end{array}\right.
$$

where $b_{k}=\frac{1}{k+1} \geq 0$ for $k \geq 1, p(t)=\frac{\ln (t+2)}{\ln (t+1)}, t_{k}=k, \tau=3$ and $\sigma=2$. If we choose $s_{n}=3 n+1$ for $n=1,2,3, \cdots$ then $s_{n} \in\left(t_{n}, t_{n+1}\right]$ and $s_{n+1}-s_{n}=3=\tau$. Hence, all conditions of Lemma 2.1 are satisfied. Clearly,

$$
p\left(s_{j}\right)=p(3 j+1)=\frac{\ln (3 j+3)}{\ln (3 j+2)} \leq \frac{\ln (j+3)}{\ln (j+2)}, j=1,2,3, \cdots,
$$

implies that

$$
\begin{aligned}
\sum_{i=1}^{\infty} \prod_{j=1}^{i} \frac{1+b_{j}}{p\left(s_{j}\right)} & \geq \sum_{i=1}^{\infty} \prod_{j=1}^{i} \frac{j+2}{j+1} \cdot \frac{\ln (j+2)}{\ln (j+3)} \\
& =\frac{\ln 3}{2} \sum_{i=1}^{\infty} \frac{(i+2)}{\ln (i+3)}=\infty
\end{aligned}
$$

Now, $t_{k+1}-t_{k}=1 \geq T$ for $k=1,2, \cdots$. Let's choose $T>h+\frac{1}{2}$ for $0<h<\frac{1}{2}$. Then for $t_{k}=k$ and $t_{k}^{+}=k+h$

$$
\begin{aligned}
\limsup _{k \rightarrow \infty}\left(\frac{1}{1+b_{k}} \int_{t_{k}}^{t_{k}+T}(2+s) d s\right) & \\
& \geq 2(T-h) \limsup _{k \rightarrow \infty}\left(\frac{k+2}{k+1}\right)=2(T-h)>1 .
\end{aligned}
$$

Consequently, $\left(A_{1}\right)$ and $\left(A_{2}\right)$ hold true. Thus by Theorem 2.3 , every solution of the system (11) is oscillatory.

Example 2.9. Consider the system

$$
\left\{\begin{array}{l}
\left(y(t)-\frac{\ln (t+1)}{\ln (t)} y(t-2)\right)^{\prime}+\left(1+t^{2}\right) y(t-3)\left(2+|y(t-3)|^{\mu}\right)=0, t \geq 2 \\
y\left(t_{k}^{+}\right)=\frac{k}{k+1} y\left(t_{k}\right), k=1,2,3, \cdots
\end{array}\right.
$$

where $-1 \leq b_{k}=-\frac{1}{k+1} \leq 0, p(t)=\frac{\ln (t+1)}{\ln (t)}, t_{k}=2 k$ for $k \geq 1, \tau=2$ and $\sigma=3$. If we choose $s_{n}=2 n+1$ for $n=1,2,3, \cdots$, then $s_{n} \in\left(t_{n}, t_{n+1}\right]$ and $s_{n+1}-s_{n}=2=\tau$. Hence, all conditions of Lemma 2.2 are satisfied. Clearly,

$$
p\left(s_{j}\right)=p(2 j+1)=\frac{\ln (2 j+2)}{\ln (2 j+1)} \leq \frac{\ln (j+2)}{\ln (j+1)}, j=1,2,3, \cdots,
$$


implies that

$$
\begin{aligned}
\sum_{i=1}^{\infty} \prod_{j=1}^{i} \frac{1}{p\left(s_{j}\right)} & \geq \sum_{i=1}^{\infty} \prod_{j=1}^{i} \frac{\ln (j+1)}{\ln (j+2)} \\
& =\sum_{i=1}^{\infty} \frac{\ln 2}{\ln (i+2)}=\infty .
\end{aligned}
$$

Now, $t_{k+1}-t_{k}=2 \geq T$ for $k=1,2, \cdots$. Let's choose $T>2 h+\frac{1}{2}$ for $0<h<\frac{1}{2}$. Then for $t_{k}=2 k$ and $t_{k}^{+}=2(k+h)$

$$
\limsup _{k \rightarrow \infty}\left(\int_{t_{k}}^{t_{k}+T}\left(1+s^{2}\right) d s\right) \geq \limsup _{k \rightarrow \infty}\left(\int_{t_{k}}^{t_{k}+T} d s\right)=T-2 h>\frac{1}{2} .
$$

Consequently, $\left(A_{1}\right)$ and $\left(A_{8}\right)$ hold true. Thus by Theorem 2.6, every solution of the system (12) oscillates.

\section{ACKNOWLEDGMENTS}

S.S. Santra was supported by the Department of Science and Technology (DST), New Delhi, India, through the bank instruction order No. DST/INSP IRE Fellowship/2014 /140, dated Sept. 15, 2014. Also, S. S. Santra was supported by DST (India Govt.) and British Council (British Govt.), under the Newton Bhabha Ph.D. placement programme, through the letter No. DST/INSPIRE/NBHF/2017/5, dated Feb. 13, 2018. The authors would also like to thank Jan Sieber (University of Exeter) for input and discussions on several technical aspects of the manuscript.

\section{REFERENCES}

[1] R. P. Agarwal, F. Karakoc, A survey on oscillation of impulsive delay differential equations, Compu. Math. Appl., 60 (2010), 1648-1685.

[2] D. D. Bainov, M. B. Dimitrova, Oscillatory properties of the solutions of impulsive differential equations with a deviating argument and nonconstant coefficients, Rocky Mountain J. Math., 27 (1997), 1027-1040. 
[3] D. D. Bainov, M. B. Dimitrova, A. B. Dishliev, Oscillation of the solutions of impulsive differential equations and inequalities with a retarded argument, Rocky Mountain J. Math., 28 (1998), 25-40.

[4] L. Berezansky, E. Braverman, Oscillation of a linear delay impulsive differential equations, Comm. Appl. Nonlinear Anal., 3 (1996), pp. 61-77.

[5] M. P. Chen, J. S. Yu, J. H. Shen, The persistence of nonoscillatory solutions of delay differential equations under impulsive perturbations, Commput. Math. Appl., 27 (1994), 1-6.

[6] K. Gopalsamy, B. G. Zhang, On delay Differential Equations with impulses, J. Math. Anal. Appl., 139 (1989), 110-122.

[7] I. Gyori, G. Ladas, Oscillation Theory of Delay Differential Equations with Applications, Clarendon Press, Oxford, 1991.

[8] J. R. Greaf, J. H. Shen, I. P. Stavroulakis, Oscillation of impulsive neutral delay differential equations, J. Math. Anal. Appl., 268 (2002), 310-333.

[9] K. Guan, J. Shen, Asymptotic behavior of solutions of a first-order impulsive neutral differential equation in Euler form, Appl. Math. Lett., 24 (2011), 1218-1224.

[10] V. Lakshmikantham, D. D. Bainov, P. S. Simieonov, Oscillation Theory of Impulsive Differential Equations, World Scientific, Singapore, 1989.

[11] Z. Luo, Z. Jing, Periodic boundary value problem for first-order impulsive functional differential equations, Compu. Math. Appl., 55 (2008), 20942107.

[12] J. Li, J. Shen, Positive solutions for three-point boundary value problems for second-order impulsive differential equations on infinite intervals, $J$. Comp. Appl. Math., 235 (2011), 2372-2379.

[13] J. H. Shen, On the existence of nonoscillatory solutions of delay differential eqations with impulses, Appl. Math. Comput., 77 (1996), 153-165.

[14] J. H. Shen, Z. C. Wang, Oscillation and asymptotic behaviors of solutions of delay differential eqations with impulses, Ann. Differential Eqations, 10 (1994), 61-69. 
[15] J. Shen, Z. Zou, Oscillation criteria for first order impulsive differential equations with positive and negative coefficients, J. Comp. Appl. Math., 217 (2008), 88-37.

[16] G. Song, Y. Zhao, X. Sun, Integral boundary value problems for first order impulsive integro-differential equations of mixed type, J. Comp. Appl. Math., 235 (2011), 2928-2935.

[17] J. Tariboon, Boundary value problems for first order functional differential equations with impulsive integral conditions, J. Compu. Appl. Math., 234 (2010), 2411-2419.

[18] A. K. Tripathy, Oscillation criteria for a class of first order neutral impulsive differential-difference equations, J. Appl. Anal. Compu., 4 (2014), 89-101.

[19] A. K. Tripathy, S. S. Santra, Necessary and sufficient conditions for oscillation of a class of first order impulsive differential equations, Funct. Diff. Equ., 22, No. 3-4 (2015), 149-167.

[20] A. K. Tripathy, S. S. Santra, S. Pinelas, Necessary and sufficient condition for asymptotic behavior of solutions of a class of first order impulsive systems, Adv. Dyn. Syst. Appl., 11 (2016), No. 2, 135-145.

[21] A. K. Tripathy, S. S. Santra, Oscillation properties of a class of second order impulsive systems of neutral type, Funct. Diff. Equ., 23, No. 1-2 (2016), 57-71.

[22] A. K. Tripathy, S. S. Santra, Pulsatile constant and charecterization of first order neutral impulsive differential equations, Commu. Appl. Anal., 20 (2016), 65-76.

[23] A. K. Tripathy, S. S. Santra, Characterization of a class of second order neutral impulsive systems via pulsatile constant, Diff. Equ. Appl., 9, No. 1 (2017), 87-98.

[24] G. Wang, L. Zhang, G. Song, Extremal solutions for the first order impulsive functional differential equations with upper and lower solutions in reversed order, J. Comp. Appl. Math., 235 (2010), 325-333. 
[25] X. Wang, J. Zhang, Impulsive anti-periodic boundary value problem of first-order integro-differential equations, J. Comp. Appl. Math., 234 (2010), 3261-3267.

[26] Y. Zhang, A. Zhao, J. Yan, Oscillation Criteria for impulsive delay differential equations, J. Math. Anal. Appl., 205 (1997), 461-470.

[27] L. Zhang, Boundary value problem for first order impulsive functional integro-differential equations, J. Comp. Appl. Math., 235 (2011), 24422450 . 